\title{
The Regional Virtual Power Plant - Experiences of a field test
}

\author{
Joachim Seifert ${ }^{1, *}$, Paul Seidel ${ }^{1}$, Jens Werner $^{2}$, and Andrea Meinzenbach ${ }^{1}$ \\ ${ }^{1}$ TU Dresden, Faculty of Mechanical Science and Engineering, 01062 Dresden, Germany \\ ${ }^{2}$ TU Dresden, Faculty of Electrical and Computer Engineering, 01062 Dresden, Germany
}

\begin{abstract}
Due to the energy system transformation initiated by the German government, the energy supply structures will be much more decentralized in the future. In the following publication the methodology of a Regional Virtual Power Plant will be described and first results from a field test will be presented.
\end{abstract}

\section{Introduction}

During the next years the European energy sector will be changed fundamentally. Today most of the electrical power is produced in big centralized units. These units are connected to the high voltaic grid, which distributes the energy to the low voltage grid and finally to the consumer. In accordance to the transition of the energy sector (higher percentage of renewable energy) more decentralized smaller units were installed in the local energy distribution net (see figure 1).

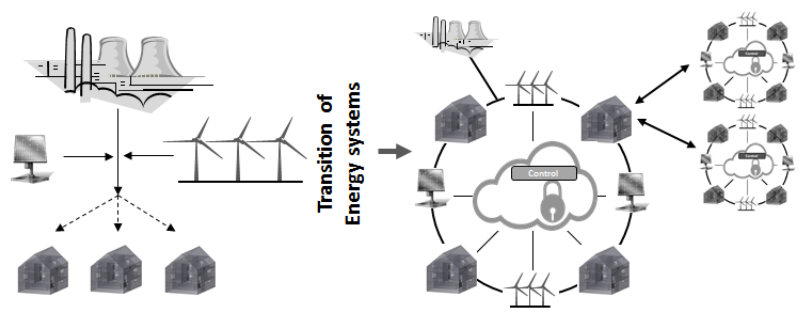

Fig. 1. centralized and decentralized energy system [2]

These units can be connected directly to the heat market in form of local consumption. Important for these decentralized systems is, that the different energy units are connected to central control-units.

These central control units collect data from the different energy devices and send out control signals, so that the power quality aspects were fulfil in the complete low voltage grid. The operation mode of the local machines is in the regional virtual power plant not heat-oriented. It is oriented on the requirements of the electrical grid to absorb renewable energy.

During the last 3 years a Regional Virtual Power Plant (RVK) was installed and operated in the region around Oldenburg in Germany. The following paper describes the basic structure, the installation and the operation of this RVK-System.

\section{Basic structure of the RVK-System}

The idea of the RVK-system is the combination of local heating aspects with aspects of the electrical grid. In particular, the electrical low-voltage network is addressed. Figure 2 shows the principal structure of the Regional Virtual Power Plant.

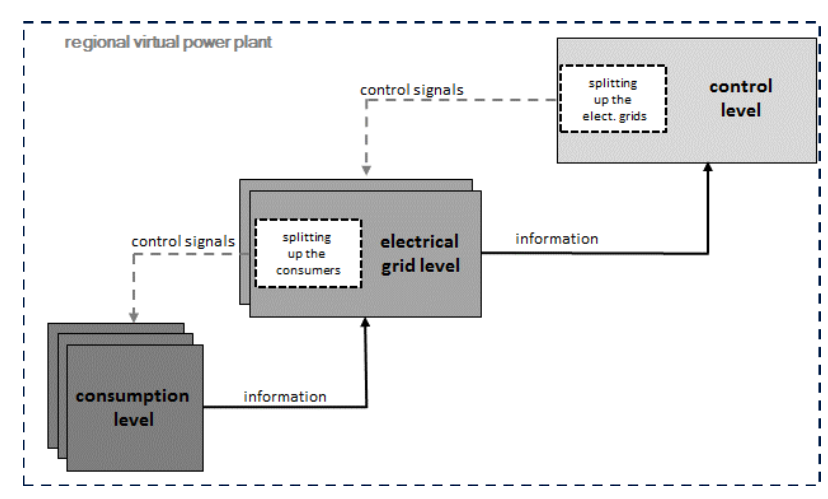

Fig. 2. centralized and decentralized energy system [1]

The consumption level represents the building in a low voltage grid. Inside the buildings different generators were installed. For the field test CHP-units (heat and power units), condensing boilers and full cells were installed. In principal the RVK-system is from the technical point of view neutral. That means that also photovoltaic-systems, heat pump systems or other generating units can be installed. Important for the RVKsystems is, that the local units, alone or in combination, must fulfil the thermal requirements in the building. That means the room temperatures and the domestic hot water heating must be provided.

\footnotetext{
*Corresponding author: joachim.seifert@tu-dresden.de
} 
With a fuel cell or a CHP-unit the thermal production is coupled on a production of electrical power. This electrical power is consumed in the building but in a second way is also feed into the low-voltage electrical grid. This is an important point of the RVK-System because with the coupling of the local heat generators to the electrical grid the local units can relieve the load on the low-voltage grid.

Based on figure 2 on the consumption level a forecast of thermal and electrical consumption and production is carried out. The characteristic values were transfer in an energy vector. This vector will transfer to the second level (electrical grid level). On the second level additional information from the electrical grid will be considered and the local timetable will be monitored and if necessary corrected. Then the combined information will be send to the central control system (third level). On the third level is the connection to the energy market. If a contract is concluded, the control centre has to ensure that the timetables are complied with at the local level. That means the control centre prepares the roadmap for the local power generation facilities. The limitations of the low-voltage grid are taken into account here.

The local thermal forecast is decisive for the functionality of the RVK-System. For this purpose, a trend method is used which determines the thermal demand of the future days on the base of the consumption of the past days. As a result, the thermal demand can be used to determine the electrical generation. The used algorithm is based on the following equations:

$$
\begin{gathered}
Q_{d+1}=m \cdot \vartheta_{a, d+1}+t \\
m=\frac{\sum_{i=1}^{n}\left(\vartheta_{a, i}-\bar{\vartheta}_{a}\right) \cdot\left(Q_{i}-\bar{Q}\right)}{\sum_{i=1}^{n}\left(\vartheta_{a, i}-\bar{\vartheta}_{a}\right)^{2}} \\
t=\bar{Q}+m \cdot \bar{\vartheta}_{a}
\end{gathered}
$$

The algorithm of the trend-method is shown in equation 1, where the future heat demand $Q_{d+1}$ depending on the future outside temperature $\vartheta_{a, d+1}$ in a linear equation with a rise and an offset. These parameters (rise $\mathrm{m}$ /offset $\mathrm{t}$ ) will be calculated (equations 2 and 3 ) with the influencing factors of measured thermal consumption $Q_{i}$ and outside temperatures $\vartheta_{a, i}$ in a fixed time interval in the past with the method of the smallest error square.

The parameters $\bar{Q}$ and $\bar{\vartheta}_{a}$ presents the mean value of the past interval. For this calculation forecast weather data is needed, which can be obtained by DWD (German Meteorological Service) or free providers (for example openweathermap.org).

\section{Installation / Test of the RVK-System}

\subsection{Installation}

The new regional virtual power plant was installed around Oldenburg in the north-west part of Germany. The test of the system in this region was perfect qualified, as in the Oldenburg region many decentralized power generation systems, based on renewable energies, are installed.

The installation was carried out in typical one- and twofamily houses. The buildings were not new buildings (construction year between 1977 and 1998) and were inhabited by 2-6 persons. Figure 3 shows the location and some representative pictures of the used buildings.

To make the installation of the RVK-System simpler, a unified system was developed. Figure 4 shows the structure of the local energetic system in the buildings. For the field test 17 buildings have been equipped with the same technology.

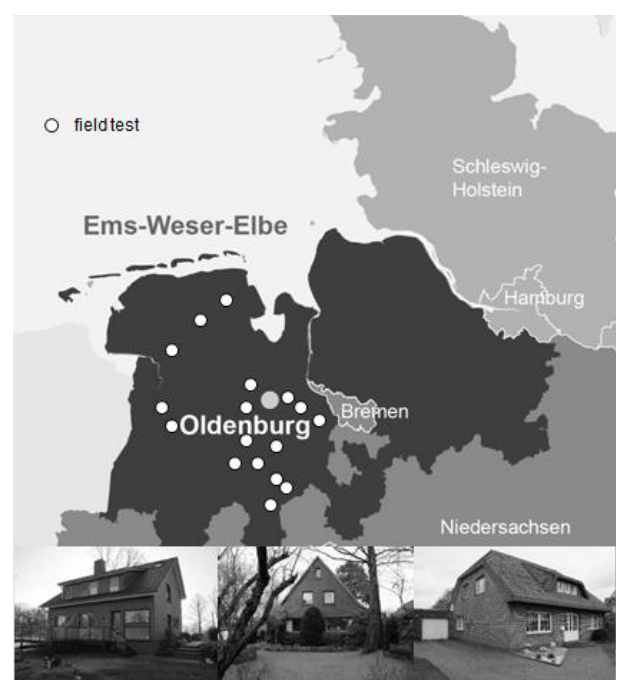

Fig. 3. Installation locations of the regional virtual power plant [2]

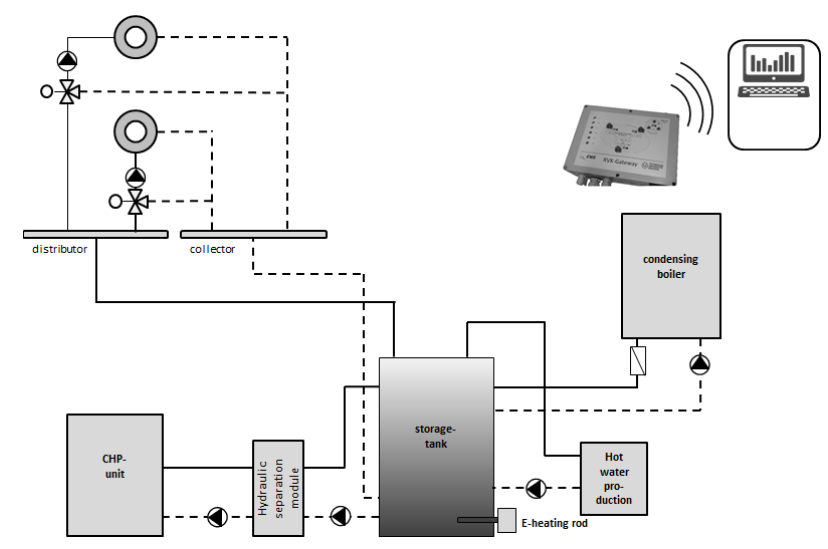

Fig. 4. Structure of the installed heating system [2] 


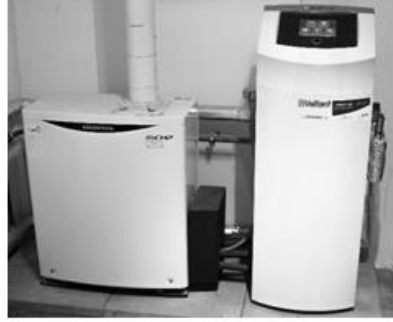

CHP-Unit

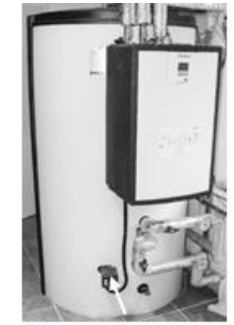

thermal storage tank with electric heating rod

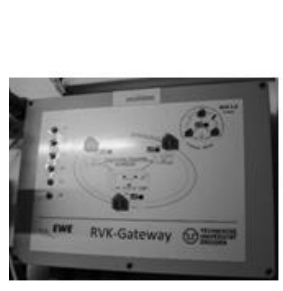

RVK-Gateway

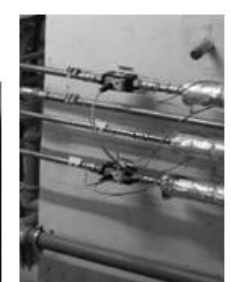

flow rate sensors

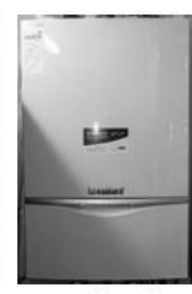

condensing boiler
Fig. 5. Local installed components of the RVK-System [2]

An important component of the local power supply system is the RVK-Gateway. The gateway is not a gateway in the classical sense. It is more a local control unit which

1. collect all the temperatures, mass flow rates and electrical values from the system

2. calculate energetically relevant comparative quantities

3. calculate a thermal and electrical forecast

4. build the energy vector

5. and organised the communication with the central control-unit.

The RVK-Gateway was a new development during the research project. From the local system to the central control-unit, also called as the backend, the communication based on the protocol IEC 60780-5-104 [4].

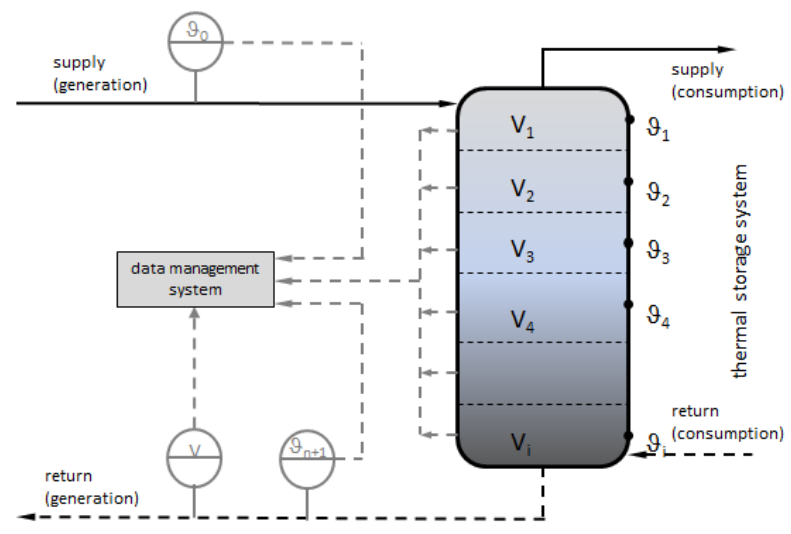

Fig. 6. Storage tank with the installed measurement equipment [2]
The thermal forecast is based on the energy content of the central thermal storage tank. Therefore, the temperature of the storage tank was measured in detail. In the existing buildings it was not possible to install a temperature measurement system inside the storage tank. Therefore, the temperature measurement systems were installed on the outside of the storage tank below the insulation. Figure 6 shows a schematic picture of the installation. Every $\mathrm{h}=10 \mathrm{~cm}$ the temperature was measured. Experiments on a certified test bench showed that the temperature determination could be realized with a deviation of $5 \%$ compared to an internal measurement.

\subsection{Test procedure}

Different functional tests were carried out with the installed RVK-System. The first functional test was the heat-guided operation of the systems with a monitoring of the distributed generation units by the central-unit. The second test was the RVK operation, where the central-unit transmitted a timetable to the local generation units but did not control it. The third test case was identical to the second but a timetable monitoring was guaranteed by the central control unit. The various test cases have been designated as:

1. heated controlled operation

2. electrical power optimized operation

3. regional virtual power plant operation

\section{Results from the field test}

The following chapter presents the main results of the field test. Detailed information's can be found in [2] and [3].

\subsection{Data availability}

Within the field test, data availability is an important criterion for the functionality of the RVK-system. Figure 7 shows the data availability during the field test for all 17 gateways.

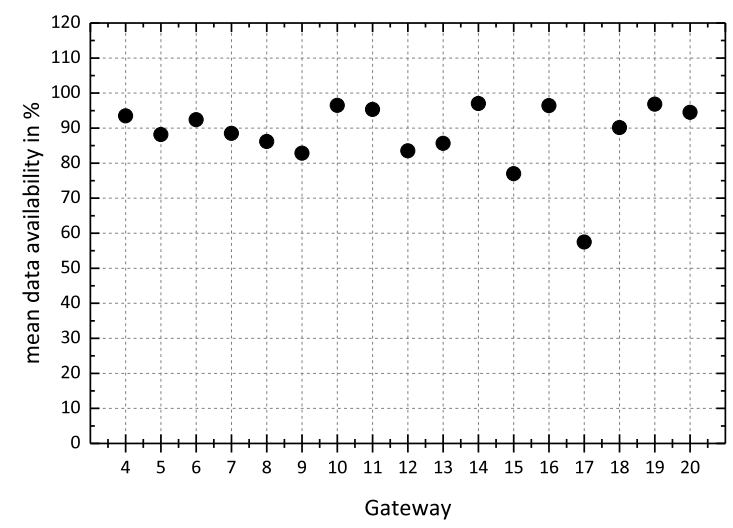

Fig. 7. Data availability of the RVK system [2] 
The documented data shows, that for a lot of buildings (gateways) the data availability is around $90 \%$ of the complete time. Only one building (gateway) has a value lower than $60 \%$. During the field test gateway 17 was not active. Therefore, the value is so low compare to the other systems. Interesting is, that a value of $100 \%$ was not reached by any system. The reason for this was, that the local CHP-units have an internal control algorithm, which will shut down the system for a certain period of time (after a switch-off, protective function). Additional reasons are defective sensors and an interrupted communication connection.

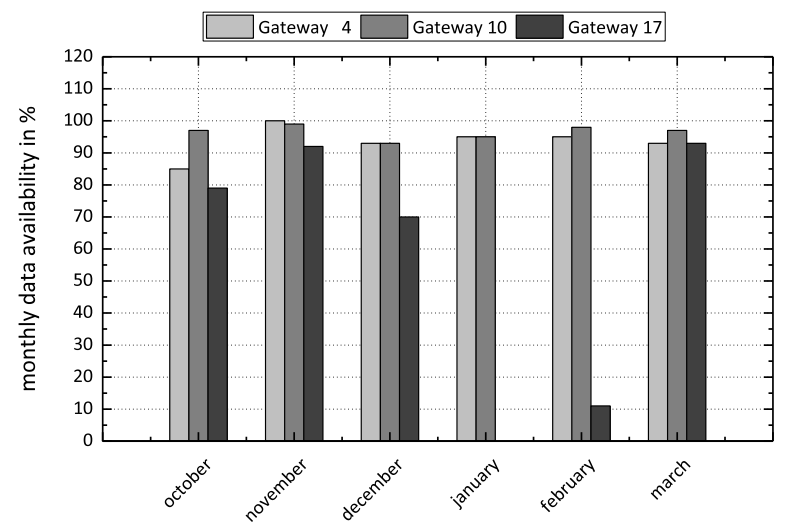

Fig. 8. Data availability of different RVK Systems - monthly [3]

Figure 8 shows detailed results for selected buildings during October 2016 and March 2017, where the offline gateway 17 is recognizable. After a maintenance application in February the gateway was in operation mode and online again.

The data and connection availability is important for a correct operating of the RVK-system. Therefore, the number of connection breaks and the time of communication failures where analysed. Figure 9 shows the mean number of connection breaks and their daily appearance. In average 2 decentral systems are shortterm offline every time. In the night (between 23:00 and 4:00 o'clock) this number is much higher, with a top at 2:00 o'clock. Maybe this is an effect of the automatic daily reboot of the internet router.

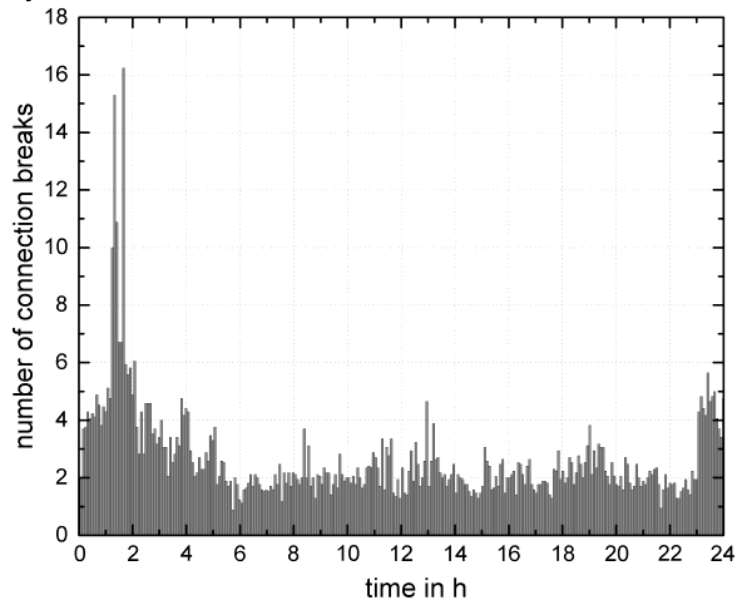

Fig. 9. Mean number of connection breaks sorted by time daily [3]
In consideration of the controllability of the decentral CHP-units the time of a communication failure is deciding (showing in table 1).

Table 1 Communication failures divided by time [3]

\begin{tabular}{|l|c|}
\hline Time period & proportion of failures in \% \\
\hline$\tau \leq 15 \mathrm{~s}$ & 26,2 \\
\hline $15 \mathrm{~s}<\tau \leq 30 \mathrm{~s}$ & 6,6 \\
\hline $30 \mathrm{~s}<\tau \leq 1 \mathrm{~min}$ & 9,6 \\
\hline $1 \mathrm{~min}<\tau \leq 2 \mathrm{~min}$ & 42,7 \\
\hline $2 \min <\tau \leq 5 \mathrm{~min}$ & 7,2 \\
\hline $5 \min <\tau \leq 30 \mathrm{~min}$ & 4,3 \\
\hline $30 \mathrm{~min}<\tau \leq 2 \mathrm{~h}$ & 2,1 \\
\hline $2 \mathrm{~h}<\tau \leq 24 \mathrm{~h}$ & 1,0 \\
\hline$\tau>24 \mathrm{~h}$ & 0,2 \\
\hline
\end{tabular}

The main communication failures are shorter than $\tau=2$ minutes with $85,1 \%$. In view of the field test with a prototype of the communication box is this a very good value, because the controlling and management of the CHP-units by the central Control-unit is only troublefree possible, if the connection failures (offline time) are lower than 2 minutes.

In all, the availability of CHP reached $97,3 \%$ and the availability of RVK gateway reached 83,2 \% (prototype, without long time failures 95,2 \%). The failure of recorded measurement and calculation data was lower than $3 \%$. It should be noted, that 150 data points per $10 \mathrm{~s}$ where recorded.

\subsection{Energetic values}

The energetic values for the three different mode of operations are documented in table 2 and 3 . The following equations are showing the definition of the fuel efficiency of the installed system consisting of CHP and condensing boiler.

CHP-unit:

$$
\begin{gathered}
\beta_{C H P, e l, i}=\frac{\int P_{C H P, e l} d \tau}{\int \dot{Q}_{C H P, B G, i} d \tau} \\
\beta_{C H P, \text { total }, i}=\frac{\int P_{C H P, e l} d \tau+\int \dot{Q}_{C H P, t h} d \tau}{\int \dot{Q}_{C H P, B G, i} d \tau}
\end{gathered}
$$

Condensing boiler:

$$
\beta_{C B, t h, i}=\frac{\int \dot{Q}_{C B, t h} d \tau}{\int \dot{Q}_{C B, B G, i} d \tau}
$$

Complete local system:

$$
\beta_{s y s, g e s, i}=\frac{\int P_{C H P, e l} d \tau+\int \dot{Q}_{h e a t} d \tau+\int \dot{Q}_{H W} d \tau}{\int \dot{Q}_{C H P, B G, i} d \tau+\int \dot{Q}_{C B, B G, i} d \tau}
$$


Table 2 Energy efficiency values for different modes of operation [3]

\begin{tabular}{|l|c|c|c|c|}
\hline Period & symbol & $\begin{array}{c}\text { heat- } \\
\text { controlled } \\
\text { operation }\end{array}$ & $\begin{array}{c}\text { electrical } \\
\text { power } \\
\text { optimized } \\
\text { operation }\end{array}$ & $\begin{array}{c}\text { regional } \\
\text { virtual } \\
\text { power plant } \\
\text { operation }\end{array}$ \\
\hline $\begin{array}{l}\text { Winter } \\
3,4^{\circ} \mathrm{C} \leq \vartheta_{\mathrm{a}} \leq \\
7,8^{\circ} \mathrm{C}\end{array}$ & $\beta_{\text {sys,i }}$ & $82,4 \%$ & $81,2 \%$ & $77,9 \%$ \\
\hline $\begin{array}{l}\text { spring } / \\
\text { summer } \\
15,3^{\circ} \mathrm{C} \leq \vartheta_{\mathrm{a}} \\
\leq 17,6^{\circ} \mathrm{C}\end{array}$ & $\beta_{\text {sys,i }}$ & $63,5 \%$ & $59,3 \%$ & $48,2 \%$ \\
\hline Average & $\beta_{s y s, i}$ & $\mathbf{7 3 , 3} \%$ & $\mathbf{6 9 , 0} \%$ & $\mathbf{6 3 , 0} \%$ \\
\hline
\end{tabular}

Table 3 Energy efficiency values for different modes of operation - detailed specification [3]

\begin{tabular}{|l|c|c|c|c|}
\hline Unit & symbol & $\begin{array}{c}\text { heat- } \\
\text { controlled } \\
\text { operation }\end{array}$ & $\begin{array}{c}\text { electrical } \\
\text { power } \\
\text { optimized } \\
\text { operation }\end{array}$ & $\begin{array}{c}\text { regional } \\
\text { virtual } \\
\text { power plant } \\
\text { operation }\end{array}$ \\
\hline \multirow{2}{*}{$\mathrm{CHP}$} & $\beta_{\mathrm{CHP}, \mathrm{el}, \mathrm{i}}$ & $23,0 \%$ & $22,6 \%$ & $22,3 \%$ \\
\cline { 2 - 5 } & $\beta_{\mathrm{CH}, \mathrm{total}, \mathrm{i}}$ & $79,0 \%$ & $74,9 \%$ & $74,3 \%$ \\
\hline $\begin{array}{l}\text { Condensing } \\
\text { boiler }\end{array}$ & $\beta_{\mathrm{CB}, \mathrm{i}}$ & $\mathbf{7 7 , 7} \%$ & $\mathbf{7 6 , 2} \%$ & $\mathbf{7 4 , 5 \%}$ \\
\hline $\begin{array}{l}\text { complete } \\
\text { system }\end{array}$ & $\beta_{\mathrm{sys}, \mathrm{i}}$ & $\mathbf{7 3 , 3} \%$ & $\mathbf{6 9 , 0} \%$ & $\mathbf{6 3 , 0} \%$ \\
\hline
\end{tabular}

The documented values from table 1 shows that for a comparison of the different control strategies distinction is necessary. The highest values can be documented for the heat controlled operation. The reason for this is, that for the electrical power optimization mode and for the regional virtual power plant operation the system often clocks, i.e. frequent states of approach are to be indicated. Significant is also the dependence on the season. Analysing the data from table 2 it can be stated, that the CHP-unit has only for the thermal values and dependence on the selected operating mode. The electrical side is nearly independent.

\subsection{Functional test}

With the Regional Virtual Power Plant different functionality tests are carried out. One important question during the field test was: Is the RVK-System capable of providing control power? Therefore, a test scenario was created for the retrieval of minute control power. This part of control power can be implemented by distributed small CHP-units. Exemplary figure 10 shows the results of this test.

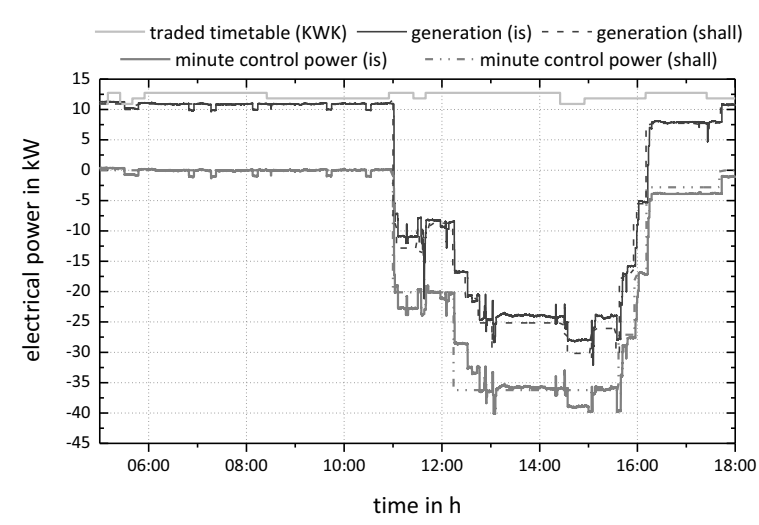

Fig. 10. Test case - MRL retrieval [3]

During a time until 11 a.m. the CHP units are on and the RVK-systems can provide approx. $\mathrm{P}=11 \mathrm{~kW}$ of electrical power. At 11 a.m. a negative retrieval of control power takes place and the net electrical power of the Regional Virtual Power Plant reduce distinctly. A negative power can be provided only by the E-heating rods in the storage tank. Shortly after 12 a.m. a second power stage is called up, which can also be implemented realised by the RVKsystem. At 15:30 the negative control power switch off and the RVK-system returns to the initial state. This simplified test shows that a RVK-system with small units directly in the building can stabilise the electrical low voltage grid.

\section{Conclusions}

During the last 3 years a comprehensive field test of a Regional Virtual Power Plant was carried out. The results of the field test clearly show that such systems can only be used if a uniform and simple installation is available. The central component here is an RVK gateway with the locally determined data, which can be processed and sent to the central backend.

With regard to data availability, it was proven in the first 3 years that approx. $90 \%$ of the data required for controlling the system is available during the observation period. The aim of further development work should be to further increase this parameter. From an energetic point of view, it must be stated that a heat controlled mode of operation achieves the highest degree of mining material utilisation, as the plants are operated here without major load changes. A mode of operation with regard to the electrical network has significantly lower degrees of utilisation. The advantage here is clearly to be seen in the support for the electrical network.

\section{Acknowledgment}

This publication is based on a research projects which were supported by the German federal ministry of economics and energy under the code 03ET1280-A/B. 


\section{Symbols and abbreviations}

CHP - Cogeneration Heat and Power

CB - Condensing Boiler

RVK - Regional Virtual Power Plant

Sys - System

$\dot{Q}_{C H P, t h} \quad$ - heat of CHP

$\dot{Q}_{C B, t h} \quad$ - heat of condensing boiler

$\dot{Q}_{\text {heat }} \quad$ - room heating

$\dot{Q}_{H W} \quad$ - hot water

$\dot{Q}_{C H P, B G, i}$ - heat of fuel gas - CHP

$\dot{Q}_{C B, B G, i}$ - heat of fuel gas - CB

$P_{C H P, e l}$ - electrical power - CHP

$\beta_{C H P, e l, i}$ - electrical utilisation CHP

$\beta_{C H P, \text { total }, i}$ - total utilisation CHP

$\beta_{C B, i} \quad$ - thermal utilisation CB

$\beta_{\text {Sys, } i} \quad$ - total utilisation System

$Q_{d+1} \quad$ - forecasted heat demand

$Q_{i} \quad$ - measured heat consumption

$\vartheta_{a, d+1} \quad$ - forecasted outside temperature

$\bar{Q} \quad$ - average heat

$\bar{\vartheta}_{a} \quad$ - average outside temperature

$\vartheta_{i} \quad$ - measured outside temperature

$\mathrm{m} \quad-$ rise

$\mathrm{t} \quad-$ offset

V - volume

\section{References}

1. J. Seifert, P. Schegner, A. Meinzenbach, P. Seidel, J. Haupt, L. Schinke, J. Werner, T. Hess, Regionales Virtuelles Kraftwerk auf Basis der Mini- und MikroKWK Technologie, ISBN 978-3-8007-3654-6 (2015)

2. J. Seifert, J. Werner, P. Seidel, C. Arnold, U. Baumann, M. Drexler, J. Haupt, J. Hartmann, A. Janssen, R. Jünemann, B. Koletzek, G. Ma, L. Meinzenbach, P. Schegner, M. Schumacher, A. Tiltag, A. Tolksdorf, K.E. Wolffgang, RVK-II Praxiserprobung des Regionalen Virtuellen Kraftwerks auf Basis der Mikro-KWK Technologie, ISBN 978-3-8007-4630-9 (2018)

3. P. Seidel, Ein Beitrag zur energetischen Analyse von verteilten Energiesystemen am Beispiel von KleinKWK Anlagen (virtueller Verbund), PhD-Thesis, TU-Dresden (2018)

4. IEC 60870-5-104, Telecontrol equipment and systems - Part 5-104: Transmission protocols Network access for IEC 60870-5-101 using strandard transport profiles (2006) 